\title{
Bladder injuries frequently missed in polytrauma patients
}

\author{
This article was published in the following Dove Press journal: \\ Open Access Journal of Urology \\ 12 May 2010 \\ Number of times this article has been viewed
}

\section{Tanweer Karim \\ Margaret Topno \\ Vinod Sharma \\ Raymond Picardo \\ Ankur Hastir \\ Surgery, MGM Medical College, Kamothe, Navi Mumbai, India}

Correspondence:Tanweer Karim Associate Professor, Surgery, MGM Medical College, Sector I8, Kamothe, Navi Mumbai, India - 410209

Tel +9l 9987342687

Fax +91 2227420320

Email karimtanweer@yahoo.co.in
Abstract: Bladder injuries are very common in patients who have had road traffic accidents. The method of diagnosis and management of such injuries is well established and accepted. However, trauma to the bladder can be associated with other life-threatening injuries which are frequently missed, and often diagnosed during laparotomy for other reasons. The aim of this study was to diagnose bladder injury in polytrauma patients as early as possible, taking into consideration the fact that these patients are hemodynamically unstable and require rapid evaluation and management. In order to achieve our objective, we used bedside sonography with retrograde instillation of normal saline to diagnose bladder injury in addition to use of the conventional retrograde cystogram.

Keywords: bladder injury, bladder rupture, retrograde cystogram

\section{Introduction}

Urinary tract injuries occur in $10 \%$ to $15 \%$ of cases of blunt/penetrating abdominal trauma. Urinary bladder injuries are often associated with pelvic fractures and occur mostly due to external force. ${ }^{1}$ About $15 \%$ of all pelvic fractures are associated with concomitant bladder or urethral injuries. Fragments from the fracture site usually result in extraperitoneal bladder rupture. ${ }^{2}$ If the urine is infected, extraperitoneal bladder perforation may result in deep pelvic abscess and severe pelvic inflammation. Similarly, a direct blow to the lower abdomen may result in intraperitoneal rupture. If the diagnosis is not established immediately and urine is sterile, there may be no symptoms for several days, otherwise immediate peritonitis and acute abdomen will develop. Therefore, timely assessment of these cases is fundamental in reducing morbidity and mortality. The majority of extraperitoneal ruptures can be managed with simple catheterization (urethral or suprapubic) for 2-3 weeks. If the patient is taken to the operating theatre for associated injuries, extraperitoneal rupture may be repaired concomitantly. Intraperitoneal bladder rupture requires surgical exploration, and catheterization alone is not sufficient. ${ }^{2,3}$

Gross hematuria in the presence of a pelvic fracture is highly suggestive of a bladder injury. Diagnosis is confirmed with the help of conventional retrograde cystography and computed tomography (CT) cystography which is an excellent method for detecting bladder rupture. Although a cystogram is $95 \%$ to $100 \%$ accurate for detecting bladder perforation, it is difficult to perform in emergency conditions in a critically ill patient. The aim of this study was to diagnose bladder injury in polytrauma patients at the earliest, keeping in mind the fact that these patients are hemodynamically unstable and require rapid evaluation and management. 


\section{Material and methods}

This study was conducted at the MGM Medical College, Navi Mumbai, India, from May 2005 to May 2006. All patients included in this study were admitted for polytrauma with a history of road traffic accident or a fall from a height. In order to achieve our objective, we used a simple test (bedside sonography with retrograde instillation of normal saline) to diagnose bladder rupture. All patients underwent retrograde instillation of sterile normal saline through a Foley catheter, and bladder distension and disruption of the bladder wall were viewed on sonography. Retrograde cystography was performed in all cases subsequently, and the findings of both tests were correlated. Patients with obvious urethral injuries were not included in the study because Foley catheterization was mandatory to perform these diagnostic tests.

\section{Results}

Of 103 patients admitted with polytrauma, 22 had clinical features suggestive of bladder injuries. All 22 cases were first evaluated on sonography with retrograde instillation of the normal saline test. The test was positive in 20 cases. A conventional retrograde cystogram, subsequently done to reconfirm, was also positive in 20 patients only. Both tests were falsely negative in two cases of extraperitoneal rupture because the rent was sealed by hematoma. Rupture of urinary bladder was present in all 22 patients, 18 ruptures being extraperitoneal and four intraperitoneal.

\section{Discussion}

There is already a well established and standardized approach for the diagnosis and management of bladder injuries. However, bladder trauma is seldom an isolated injury, and is usually one part of multiple injuries. Bladder injuries are frequently missed in polytrauma cases because of attention being focused on more life-threatening injuries, eg, head injury, tension pneumothorax, hemothorax, and hemoperitoneum. ${ }^{4}$ Radiologic examination is of paramount importance and should be performed to identify and classify the injury and to plan surgical repair, but should not hinder hemodynamic stabilization of the patient.

Several radiologic evaluations are appropriate, ranging from CT cystography to basic retrograde cystography. Evaluation of the urinary bladder and free fluid in the pelvis can also be done with sonography with fair accuracy when the bladder is fully distended. The detection of peritoneal fluid in the presence of normal viscera or failure to visualize the bladder after transurethral introduction of saline is considered highly suggestive of bladder rupture. ${ }^{5}$ Abdominal CT, in general, is inferior to the retrograde cystogram as a method of detecting bladder injury, unless CT cystography is used as an adjunct to CT. As reported in various studies, $\mathrm{CT}$ abdomen has an accuracy of only $50 \%-60 \% .{ }^{6,7}$

Although a conventional retrograde cystogram is 95\%-100\% accurate in diagnosing bladder rupture, controversy persists regarding the need for a retrograde cystogram in patients without gross hematuria. Cass ${ }^{8,9}$ suggested that the presence of microscopic hematuria is an indication for an immediate retrograde cystogram, whereas Antoci and Schiff ${ }^{10}$ and Fallon et $\mathrm{al}^{11}$ stated that only gross hematuria warranted evaluation.

Irrespective of the presence or absence of an indication, it is reported that fewer than half of trauma patients are in a condition which allows diagnosis of bladder rupture by a retrograde cystogram. Moreover, accurate and rapid disposition of multiple-trauma patients is crucial for optimal outcome. We used retrograde instillation of normal saline because almost all cases of abdominal trauma undergo sonography and addition of this method at the same sitting aids the diagnosis of bladder injuries without delay and at no additional cost. Although the accuracy of the ultrasoundguided saline test needs further verification in a larger sample size, it has the advantages over the retrograde cystogram of being simply and rapidly performed (average time eight minutes), being able to be performed at the bedside in critically ill patients, having no risk of the radiation exposure associated with CT cystography, and no risk of anaphylaxis associated with contrast material.

\section{Conclusion}

A large number of bladder trauma cases are managed by general surgeons as part of care of multiple injuries. It is not possible to perform a retrograde cystogram or CT cystogram in all cases, either because of hemodynamic instability or because a decision to perform laparotomy has already been made as a result of solid organ injury or perforation peritonitis. The saline test under sonography can help to make an early diagnosis of bladder rupture with reasonable accuracy. Moreover, it is cost-effective, free of radiation exposure, and avoids the potential risk of an anaphylactic reaction associated with contrast material.

\section{Disclosure}

The authors report no conflicts of interest in this work. 


\section{References}

1. Corriere JN Jr, Sandler CM. Mechanisms of injury, patterns of extravasation and management of extraperitoneal bladder rupture due to blunt trauma. $J$ Urol. $1988 ; 139(1): 43-44$.

2. Hochberg E, Stone NN. Bladder rupture associated with pelvic fracture due to blunt trauma. Urology. 1993;41(6):531-533.

3. Bodner DR, Selzman AA, Spirnak JP. Evaluation and treatment of bladder rupture. Semin Urol. 1995;13(1):62-65.

4. Ziran BH, Chamberlin E, Shuler FD, Shah M. Delays and difficulties in the diagnosis of lower urologic injuries in the context of pelvic fractures. J Trauma. 2005;58(3):533-537.

5. Sandler CM, Francis IR, Baumgarten DA, et al. Suspected lower urinary tract trauma. In: ACR Appropriateness Criteria. Reston,VA: American College of Radiology; 2007.
6. Horstman WG, McClennan BL, Heiken JP. Comparison of computed tomography and conventional cystography for detection of traumatic bladder rupture. Urol Radiol.1991;12(4):188-193.

7. Haas CA, Brown SL, Spirnak JP. Limitations of routine spiral computerized tomography in the evaluation of bladder trauma. $J$ Urol. 1999;162(1):51-52.

8. Cass AS. Bladder trauma in the multiple injured patient. $J$ Urol. 1976;115:667-669.

9. Cass AS. The multiple injured patient with bladder trauma. J Trauma. 1984;24:731-734.

10. Antoci JP, Schiff M. Bladder and urethral injuries in patients with pelvic fractures. J Urol. 1982;128:25-26.

11. Fallon B, Wendt TC, Hawtrey E. Urological injury and assessment in patients with fractured pelvis. J Urol. 1984;131:712-714.

\section{Publish your work in this journal}

The Open Access Journal of Urology is an international, peer-reviewed, open access journal publishing original research, reports, editorials, reviews and commentaries on all aspects of adult and pediatric urology in the clinic and laboratory including the following topics: Pathology, pathophysiology of urological disease; Investigation and treatment of

\section{Dovepress}

urological disease; Pharmacology of drugs used for the treatment of urological disease. The manuscript management system is completely online and includes a very quick and fair peer-review system, which is all easy to use. Visit http://www.dovepress.com/testimonials.php to read real quotes from published authors.

Submit your manuscript here: http://www.dovepress.com/open-access-journal-of-urology-journal 